\title{
Investigation of Multifrequency Piezoelectric Energy Harvester
}

\author{
Andrius Čeponis and Dalius Mažeika \\ Department of Information Systems, Faculty of Fundamental Sciences, Vilnius Gediminas Technical University, \\ LT-10223 Vilnius, Lithuania \\ Correspondence should be addressed to Andrius Čeponis; andrius.ceponis@vgtu.lt
}

Received 1 June 2017; Accepted 31 October 2017; Published 21 November 2017

Academic Editor: Brij N. Agrawal

Copyright @ 2017 Andrius Čeponis and Dalius Mažeika. This is an open access article distributed under the Creative Commons Attribution License, which permits unrestricted use, distribution, and reproduction in any medium, provided the original work is properly cited.

\begin{abstract}
This paper presents results of numerical and experimental investigations related to the piezoelectric energy harvester that operates at multifrequency mode. Employment of such operation principle provides an opportunity for obtaining frequency response characteristics of the harvester with several resonant frequencies and in this way increasing efficiency of the harvester at a wide spectrum of excitation frequencies. The proposed design of the energy harvester consists of five cantilevers which forms square type system. Cross sections of the cantilevers are modified by periodical cylindrical gaps in order to increase strain value and to obtain more uniform strain distribution along the cantilevers. Cantilevers are rigidly connected to each other and compose an indissoluble system. Square type harvester has seismic masses at every corner. These masses are placed under specific angle in order to reduce natural frequencies of the system and to create additional rotation moments in the body of harvester. Results of the numerical investigation revealed that harvester has five resonance frequencies in the range from $15 \mathrm{~Hz}$ to $300 \mathrm{~Hz}$. Numerical analysis of the harvester revealed that the highest open circuit voltage density is $19.85 \mathrm{mV} / \mathrm{mm}^{3}$. Moreover, density of the total electrical energy reached $27.5 \mu \mathrm{J} / \mathrm{mm}^{3}$. Experimental investigation confirmed that frequency response characteristics are obtained during numerical investigation and showed that energy density of the whole system reached $30.8 \mu \mathrm{J} / \mathrm{mm}^{3}$.
\end{abstract}

\section{Introduction}

Wireless sensors, autonomous electronic systems, and modern health monitoring devices take huge part in nowadays life. Usually, such low power devices are employed to follow and control numerous physical parameters, store data, and wirelessly transfer it [1]. So, numerous advantages and usage areas of wireless, low power systems could be found. On the other hand, these systems and devices have a main disadvantage: they are mainly powered by conventional batteries. Disadvantages of the conventional batteries lead to sort operation time, high service costs, and environmental pollution. Therefore, in order to eliminate negative impact of the batteries to the wireless devices, alternative power sources should be used [2].

At this point, energy harvesting technologies take a lead and provide lifetime, environmental friendly, and relativity cheap power supply solution. In order to employ energy harvesting as power source, proper energy harvesting technology should be chosen. However, electromagnetic, electrostatic, and triboelectric energy harvesting technologies have few critical disadvantages, that is, low power density, complex construction, and demand on external power source [3-5]. On the other hand, piezoelectric energy harvesters could be characterized as scavengers with high power density, simple construction, and suitable electrical outputs [6]. So, the most common construction for piezoelectric energy harvesting is simple cantilever beam. Many authors investigated various geometrical implementation of the cantilevers [7-10]. Also, several authors were focused on possibility of improving efficiency of the cantilever by increasing strain level and its distribution along length of the beam [11-13].

Taking into consideration the efforts to find the best geometrical shape of the cantilever and improve its efficiency, the main imperfection of this construction still remains. Conventional cantilever has extremely narrow bandwidth and operates effectively only when excitation frequency falls to that range. If cantilever operates outside that range, efficiency falls down dramatically. Therefore, narrow bandwidth 
of the cantilever is the main obstacle for real-life standalone applications [14].

During the last decade, many authors put huge efforts to extend bandwidth of the energy harvesters. On the basis of these efforts, passive and active frequency tuning methods were developed [15]. In general, these methods are not suitable for standalone applications, so another possible solution is multifrequency operation principle.

Ferrari et al. proposed possibility of using array of the cantilever beams for multifrequency operation. In the proposed system, cantilevers are unrelated to each other and have different fundamental frequencies. Such design ensured much wider bandwidth compared to harvesters based on the single beam. On the other hand, efficiency of the proposed system is quite low. During frequency-dependent excitation, at particular moment, only one cantilever effectively operates; meanwhile other beams are almost useless. Such operation principle has negative influence on power density of whole system.

Abdelkefi et al. published an article related to piezoelectric energy harvester that undergoes bending-torsion vibrations. Coupling of the vibrations was achieved by asymmetrical seismic mass which creates offset between its center of gravity and shear. Authors reported that usage of shifted centers has noticeable influence on the fundamental frequencies, mode shapes, and response to excitation. Also, when the lowest fundamental frequencies become close to each other broadband response of the harvester can be observed. Parametric study of the system revealed that performance of the harvester directly is related to asymmetry of the seismic mass. Moreover, authors discovered that harvested power was increased more than $30 \%$ compared to conventional cantilever.

Erturk et al. introduced L-shaped beam-mass structure as new implementation of the energy harvester. Investigation of the L-shaped system revealed that such design has much wider broadband energy harvesting characteristics compared to the conventional cantilever. Authors claimed that L-shaped harvester can be tuned to has the first two natural frequencies much closer to each other. Also, it was found that system is less sensitive to variations in the dominant frequency compared to conventional beam.

Wu et al. published article focused on folded, M-shaped, asymmetric wideband piezoelectric harvester. Authors claimed that proposed design increases range of effective energy harvesting and has much lower demand on volume compared to conventional broadband energy harvesting systems. Numerical analysis and experimental investigation of the proposed construction showed that three fundamental frequencies are close to each other and by this way broadband energy harvesting is achieved. Authors concluded that proposed design covers frequency range from $13 \mathrm{~Hz}$ till $25 \mathrm{~Hz}$.

In this article we propose square type multifrequency energy harvester. It consists of five piezoelectric cantilevers with modified cross-sectional areas. Cantilevers are rigidly connected to each other and act as an indissoluble square type system. On every joint between cantilevers, under specific angle, seismic masses are placed. The specific angle was made in order to achieve additional lever arm for each part of the
TABLE 1: Geometrical parameters of the harvester.

\begin{tabular}{lc}
\hline Parameter & Value $(\mathrm{mm})$ \\
\hline$L_{1}$ & 17 \\
$L_{2}$ & 34 \\
$L_{3}$ & 21 \\
$L_{4}$ & 34 \\
$L_{5}$ & 21 \\
$\mathrm{PZT}_{1}$ & 5.9 \\
$\mathrm{PZT}_{2}$ & 10.8 \\
$\mathrm{PZT}_{3}$ & 17 \\
$\mathrm{PZT}_{4}$ & 6 \\
$\mathrm{PZT}_{5}$ & 6 \\
$\mathrm{PZT}_{6}$ & 10 \\
$\mathrm{PZT}_{7}$ & 10.4 \\
$\mathrm{PZT}_{8}$ & 4.6 \\
$\mathrm{PZT}_{9}$ & 5 \\
$\mathrm{PZT}_{10}$ & 22 \\
$\mathrm{PZT}_{11}$ & 11.3 \\
\hline
\end{tabular}

harvester. Hence, in order to verify operation principle and assess electrical characteristics, numerical and experimental investigations were performed. Results of the investigations revealed that energy harvester has five resonant frequencies at range from $15 \mathrm{~Hz}$ to $300 \mathrm{~Hz}$. Moreover, investigation of energy characteristics showed that system has high energy density and it is equal to $30.8 \mu \mathrm{J} / \mathrm{mm}^{3}$.

\section{The Design of the Multifrequency Harvester}

In most cases multifrequency energy harvesters are made as simple cantilever beam arrays. These arrays consist of several independent cantilevers that have different natural frequencies. Such design principle of the harvester allows obtaining several resonant frequencies located close to each other; however electric energy density of the whole system is low. Multifrequency piezoelectric harvester based on square type cantilever array is deeply investigated in this paper in order to overcome aforementioned disadvantages [16]. Design of the proposed harvester is given in Figure 1.

Energy harvester has five cantilever beams which are connected rigidly to each other and forms square type cantilever array. Five seismic masses are placed at every corner of the harvester. All seismic masses are uniform and have weight equal to $2.9 \mathrm{~g}$. Meanwhile, energy harvester is clamped to the housing plate through two supporting beams and finally both ends of the beams are fixed using M3 bolts. Also, M5 bolt (Figure 1(a) - 3) is used for rigid junction between housing plate and the host structure. Principle scheme of the harvester is presented in Figure 1(b), while geometrical parameters are given in Table 1.

Thickness of all cantilevers is $1 \mathrm{~mm}$; however, cross sections of the cantilevers are modified by periodical cylindrical gaps with radius $0.5 \mathrm{~mm}$. So, thickness of the cantilevers 


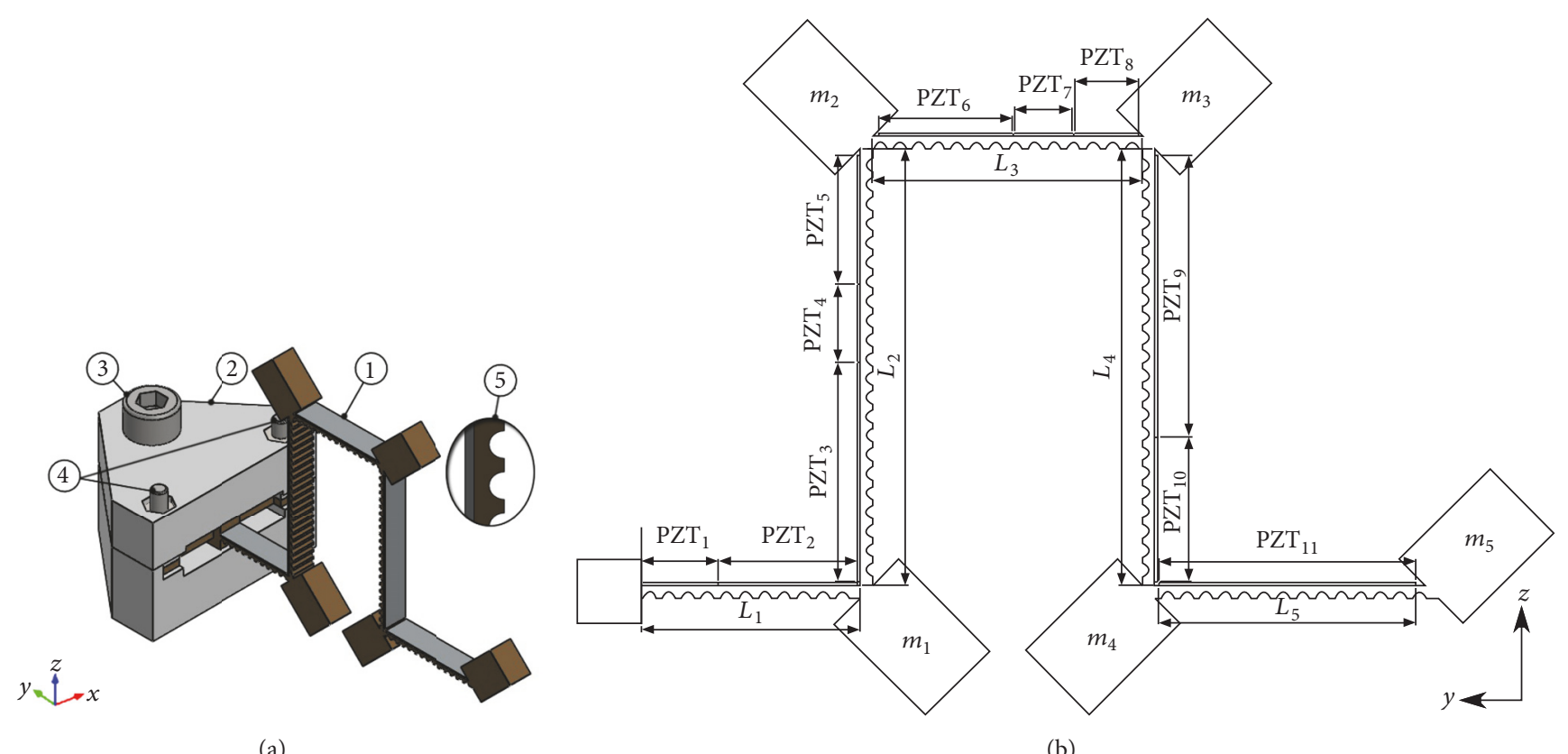

(a)

(b)

FIGURE 1: Schemes of the harvester; (a) isometric view of the harvester; 1 , bolt for clamping to the host structure; 2 , housing plate; 3 , body of the harvester made of $\mathrm{C} 17200$ beryllium bronze; 4, bolts for harvester clamping to the housing plate; 5 , cross-sectional design of the harvester; (b) principle scheme of the harvester; $\mathrm{PZT}_{1}-\mathrm{PZT}_{11}$, soft piezoceramic made of PIC255; $L_{1}-L_{5}$, lengths of cantilevers; $m_{1}-m_{5}$, seismic masses.

becomes nonlinear. Therefore, modifications of the crosssectional areas lead to improvements in strain and strain distribution across the piezoceramic layer. Also, modifications of the cross-sectional areas reduce structural damping of the system and increase sensibility of the harvester to low excitation amplitudes. Width of all cantilevers is $5 \mathrm{~mm}$ the same as the width of the seismic masses. Also, upper surfaces of the cantilevers are covered by piezoceramic layers which are divided into eleven sections. Such scheme of the piezoceramic layers is made in order to avoid charge cancelation during harvester operation at the second outof-plane bending mode as well as compounds of the first and second bending modes. Partition of the piezoceramic layers was based on the results of numerical investigation. Explanation of the piezoceramic partition principle is given in the next section.

In most cases, clamping of the energy harvesters is rigid. Such clamping is suitable for systems which operates at one resonant mode. Cantilevers of the proposed energy harvester vibrate at the first and the second out-of-plane bending modes. Moreover, compounds of these modes are used for the harvesters operation as well. So, during its operation at compounded mode, longitudinal motion of the base will be generated. Therefore, rigid clamping of the system base will damp energy harvester and usage of compounds of dominant modes will be practically ineffective. In order to reduce this disadvantage of rigid base clamping, two supporting beams were used. Scheme of the clamping is given in Figure 2.

Supporting beams were designed to operate at the first bending mode when the harvester base generates longitudinal displacement. Such operation of the clamping reduces damping of the harvester and ensures possibility of obtaining

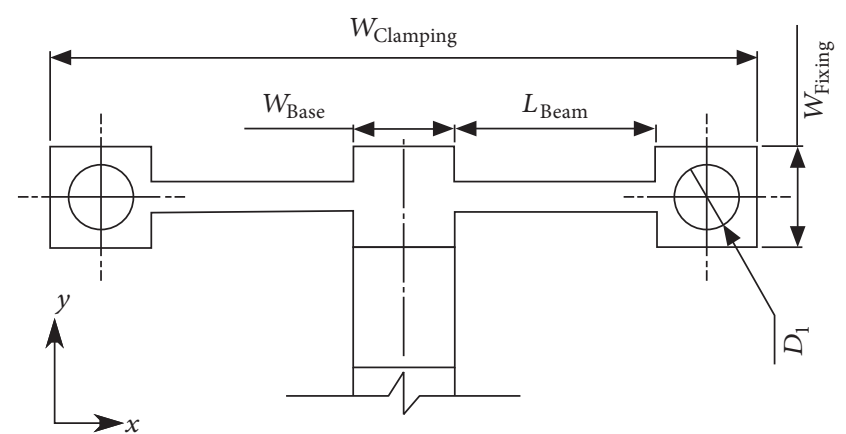

FIGURE 2: Scheme of the harvester clamping.

more efficient multifrequency operation of the harvester. So, width of the all clamping system, $W_{\text {Clamping }}$, is equal to $35 \mathrm{~mm}$. Width of the base, $W_{\text {Base, }}$, is the same as the width of the cantilevers, that is, $5 \mathrm{~mm}$. Lengths of the supporting beams were obtained by numerical investigation and become equal to $10 \mathrm{~mm}$. Width of the fixing sites, $W_{\text {Fixing, }}$, is $5 \mathrm{~mm}$ and finally diameter of the fixing holes, $D_{1}$, is $3.2 \mathrm{~mm}$.

\section{Numerical Investigation of Multifrequency Energy Harvester}

Numerical investigation of piezoelectric multifrequency square type cantilever array was performed in order to confirm operation principle and to investigate mechanical and electrical output characteristics. Finite element model (FEM) was built by employing Comsol 5.2 software. Properties of the materials used in FEM model are given in Table 2. 
TABLE 2: Material properties.

\begin{tabular}{lcc}
\hline Material properties & Beryllium Bronze C17200 & $\begin{array}{c}\text { Modified Lead Zirconate Titanate PIC255 (Physik } \\
\text { Instrumente, Germany) }\end{array}$ \\
\hline Density $\left[\mathrm{kg} / \mathrm{m}^{3}\right]$ & 8440 & 7800 \\
Young's modulus $\left[\mathrm{N} / \mathrm{m}^{2}\right]$ & $12^{10}$ & - \\
Poisson's ratio & 0.34 & 0.015 \\
Isotropic structural loss factor & 0.02 & In the polarization direction $\varepsilon_{33}{ }^{T} / \varepsilon_{0}=1200$ \\
Relative permittivity & - & Perpendicular to polarity $\varepsilon_{11}{ }^{T} / \varepsilon_{0}=1500$ \\
Elastic stiffness coefficient, $c_{33}{ }^{D}\left[\mathrm{~N} / \mathrm{m}^{2}\right]$ & - & $16.6 \cdot 10^{10}$ \\
Dielectric loss factor, tan $\delta\left[10^{-3}\right]$ & - & 20 \\
Coupling factor, $k_{31}$ & - & 0.35 \\
Piezoelectric voltage coefficient, $g_{31}\left[10^{-3} \mathrm{Vm} / \mathrm{N}\right]$ & - & -11.3 \\
\hline
\end{tabular}

Boundary conditions were set as follows; that is, ends of the supporting beams were rigidly fixed. Harmonic motion of the harvester base in $Z$ direction was used to excite host structure. Acceleration amplitude was set to $1 \mathrm{~m} / \mathrm{s}^{2}$. Probe lines for investigation of strain and its distribution were set at the center of each piezoceramic layer.

Firstly, modal analysis of the harvester was performed in order to obtain natural frequencies and modal shapes of the system. Modal shapes of the harvester in frequency ranging from $15 \mathrm{~Hz}$ to $300 \mathrm{~Hz}$ are given in Figure 3.

Analysis of the results revealed that dominant modal shapes of the beams are 1st and 2nd out-of-plane vibration modes. Moreover, modal analysis showed that system operation at the higher frequencies is based on compounds of two dominant modes. Hence, summation of the modal strains gives possibility of increasing strain and making strain distribution uniform at the piezoceramic layers. But in order to harvest electric energy in efficient way, complex partition of piezoceramic layers must be implemented. Differences between adjacent frequencies were calculated in order to assess distribution of the natural frequencies. It can be noticed that the first and the second natural frequencies have difference in 1.90 times, second and third have 3.59 times difference, third and fourth have 1.12 times, and finally fourth and fifth have difference in frequency values in 1.34 times.

According to the results of the modal analysis, it can be concluded that five natural frequencies are adequately close to each other and implement principle of multifrequency operation. Therefore, the proposed design of the multifrequency energy harvester can provide energy harvesting at five resonant frequencies which are located and range from $15 \mathrm{~Hz}$ to $300 \mathrm{~Hz}$.

Frequency domain study was used in order to investigate frequency response, strain, and its distribution characteristics. Moreover, based on strain distribution along the length of the beam, segmentation of the piezoceramic layers was made. It was done to avoid charge cancelation during systems operation at the second out-of-plane bending mode. Frequency response characteristic is given in Figure 4.

The frequency response characteristics confirmed results obtained during modal analysis. Exact coincidence of the resonant and natural frequencies shows high systems stability at different resonant frequencies. So, the highest acceleration of the harvesters tip was achieved at lowest resonant frequency with the first, out-of-plane, bending mode. On the basis of this, it can be highlighted that harvested energy density and generated voltage density at this resonant frequency will be at the highest level. Therefore, the lowest acceleration, in $Z$ direction, was obtained at resonant frequency, $50 \mathrm{~Hz}$. Such low acceleration level, in $Z$ direction, is caused by compound of two deformation modes. Therefore, at Figure 3(b), it can be observed that cantilever $L_{4}$ operates at the first, outof-plane, bending mode and as a result $L_{5}$ displacement behavior becomes longitudinal in $X$ direction. Moreover, due to specific angle of the seismic masses, additional rotation moment is created in whole body of the harvester.

Also, frequency response characteristics given in Figure 4 show that three resonant frequencies are close to each other and provide high efficiency multifrequency energy harvesting. In general, the resonant frequencies at that frequency range operate at compounded deformation modes. Such operation principle and seismic masses placed under specific angle lead to additional rotation moment in whole system and as a result all cantilevers will be strained. Hence, all cantilevers are employed during systems operation and this leads to higher energy density of the whole system. Therefore, results of the frequency response analysis revealed that proposed design of the energy harvester is able to operate at multifrequency operation principle. Moreover, compounds of deformation modes leads to modal strain summation and herewith ensures real multifrequency operation principle.

Investigation and analysis of strain and its distribution characteristics at each cantilever were performed. The goal of investigation was to obtain partition scheme of the piezoceramic layers based on strain distribution at each cantilever (Figure 5). The following algorithm was used; that is, piezoceramic layers were divided at the nodes of the higher out-of-plane bending modes. Totally 11 piezoceramic sections were obtained after numerical calculations. Such complex partition was made in order to avoid charge cancelation during systems operation at second bending mode. Calculated dimensions of the piezoceramic sections are given in Table 1.

Analyzing strain distribution at the first resonance frequency, it can be noticed that distribution is almost uniform 


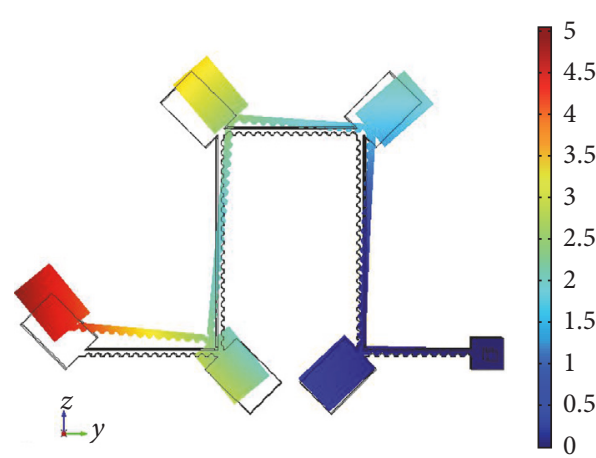

(a)

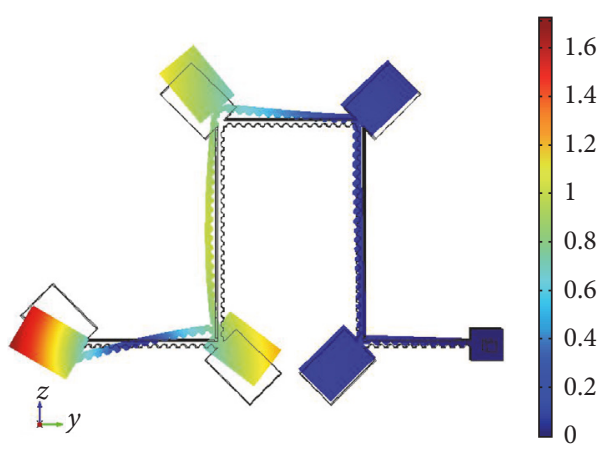

(c)

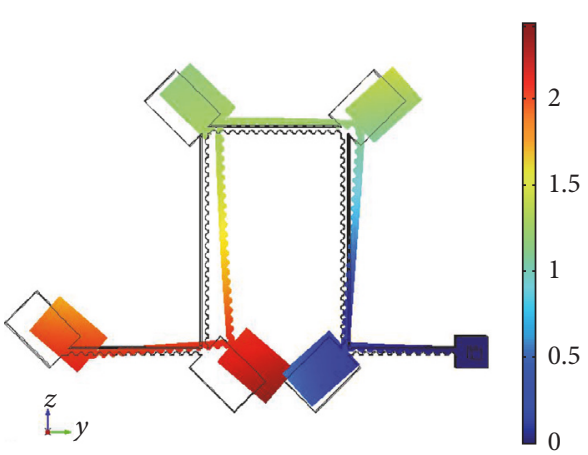

(b)

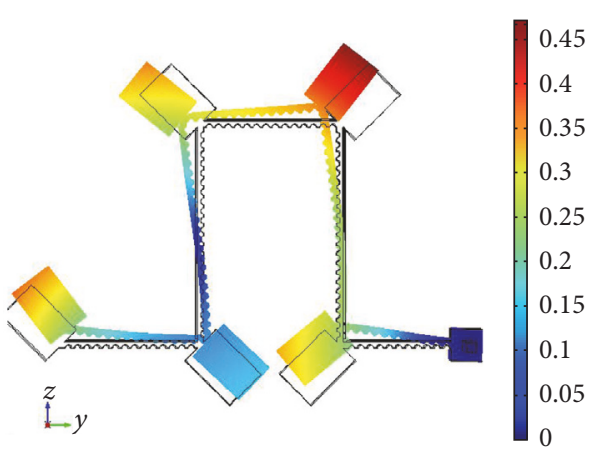

(d)

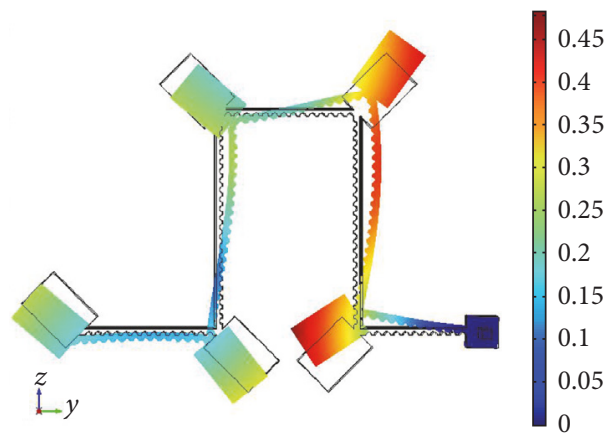

(e)

Figure 3: Modal shapes of the harvester; (a) $w_{n 1}=24.95 \mathrm{~Hz}$; (b) $w_{n 2}=47.49 \mathrm{~Hz}$; (c) $w_{n 3}=170.9 \mathrm{~Hz}$; (d) $w_{n 4}=229.3 \mathrm{~Hz}$; (e) $w_{n 5}=298.15 \mathrm{~Hz}$.

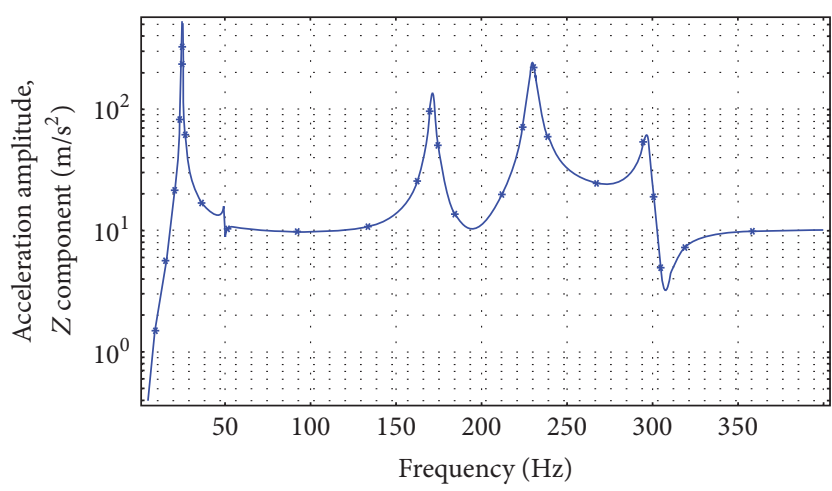

FIGURE 4: Frequency response characteristics of the harvester.

(Figure 5). This was achieved by modifying cross section with periodical gaps, modal strain summation, and seismic masses as well. Seismic masses create an additional rotation moment in the whole body of the harvester. Moreover, strain at the first resonance frequency has the highest value compared to other frequencies. So, based on this, it can be assumed that electrical characteristics at this resonant frequency will be the highest. On the other hand, strain characteristics at the higher resonance frequencies also have almost uniform distribution. However, strain values are much lower compared to the strain values at the first resonance frequency. Summary of the maximum strain values was made in order to assess strain level at every resonance frequency. Results are given in Table 3.

It can be noticed that strain maximum values of the beams are similar at every resonance frequency. Difference between the first and higher resonance frequencies is approximately 10 times. On the other hand, strain at the higher resonance frequencies is also roughly similar. It shows that electrical 


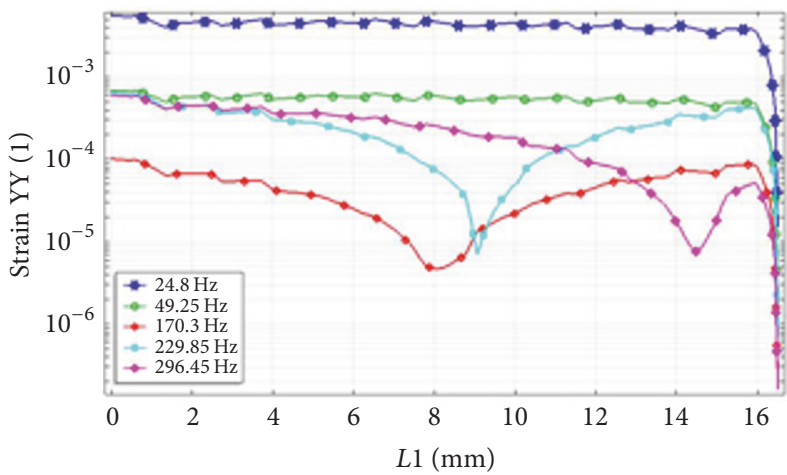

(a)

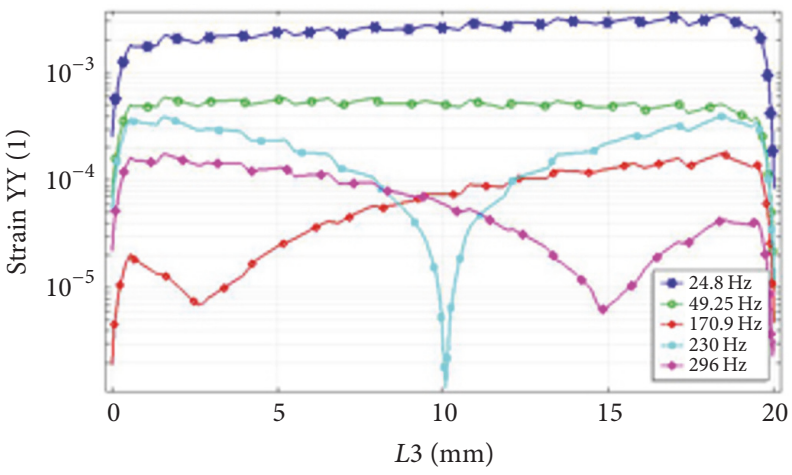

(c)

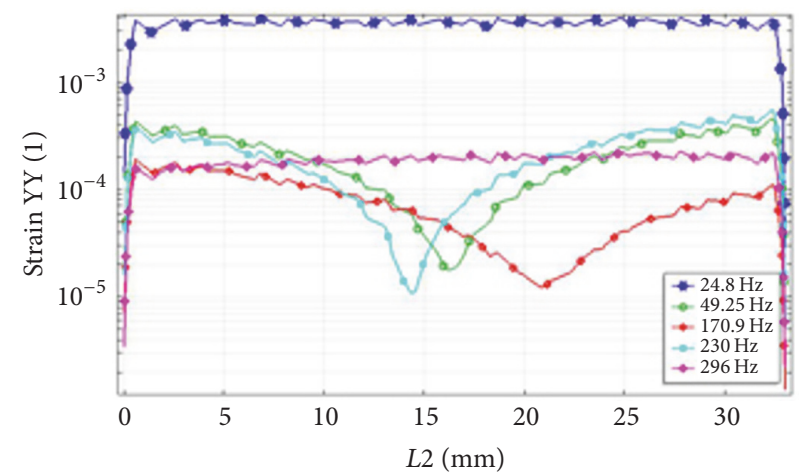

(b)

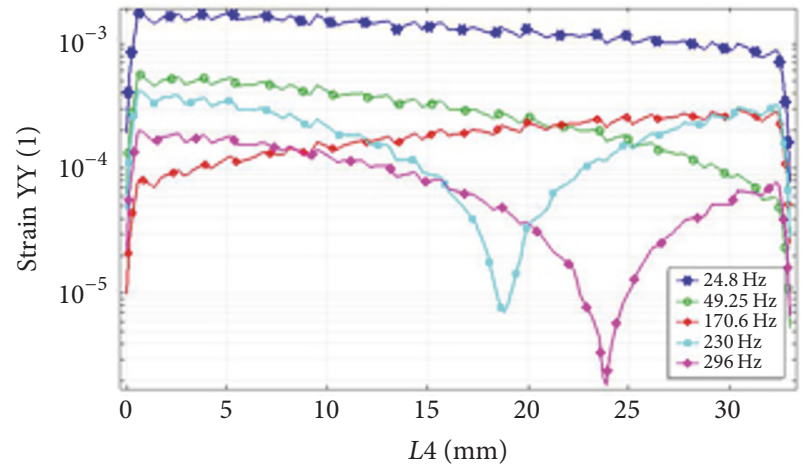

(d)

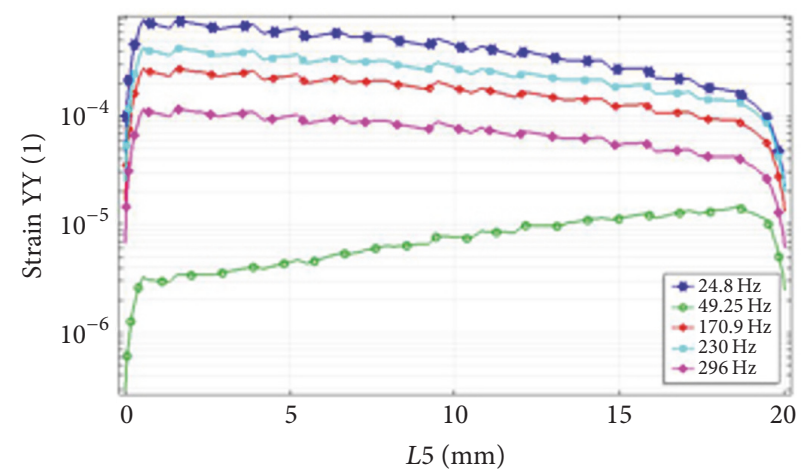

(e)

FIgURE 5: Strain characteristics; (a) strain characteristics at $L_{1}$; (b) strain characteristics at $L_{2}$; (c) strain characteristics at $L_{3}$; (d) strain characteristics at $L_{4} ;(\mathrm{e})$ strain characteristics at $L_{5}$.

TABLE 3: Summary of the maximum strain values.

\begin{tabular}{lcccc}
\hline Beam & & \multicolumn{3}{c}{ Resonant frequency $(\mathrm{Hz})$} \\
& 24.8 & 49.25 & 170.9 & 230 \\
\hline Strain at $L_{1}$ & $5.59 \cdot 10^{-3}$ & $7.43 \cdot 10^{-4}$ & $10.2 \cdot 10^{-5}$ & $4.15 \cdot 10^{-4}$ \\
Strain at $L_{2}$ & $3.88 \cdot 10^{-3}$ & $4.48 \cdot 10^{-4}$ & $2.37 \cdot 10^{-4}$ & $4.5 \cdot 10^{-4}$ \\
Strain at $L_{3}$ & $3.41 \cdot 10^{-3}$ & $5.22 \cdot 10^{-4}$ & $1.63 \cdot 10^{-4}$ & $3.72 \cdot 10^{-4}$ \\
Strain at $L_{4}$ & $1.85 \cdot 10^{-3}$ & $6.21 \cdot 10^{-4}$ & $2.84 \cdot 10^{-4}$ & $3.11 \cdot 10^{-4}$ \\
Strain at $L_{5}$ & $8.15 \cdot 10^{-4}$ & $3.42 \cdot 10^{-6}$ & $2.99 \cdot 10^{-4}$ & $4.25 \cdot 10^{-4}$ \\
\hline
\end{tabular}




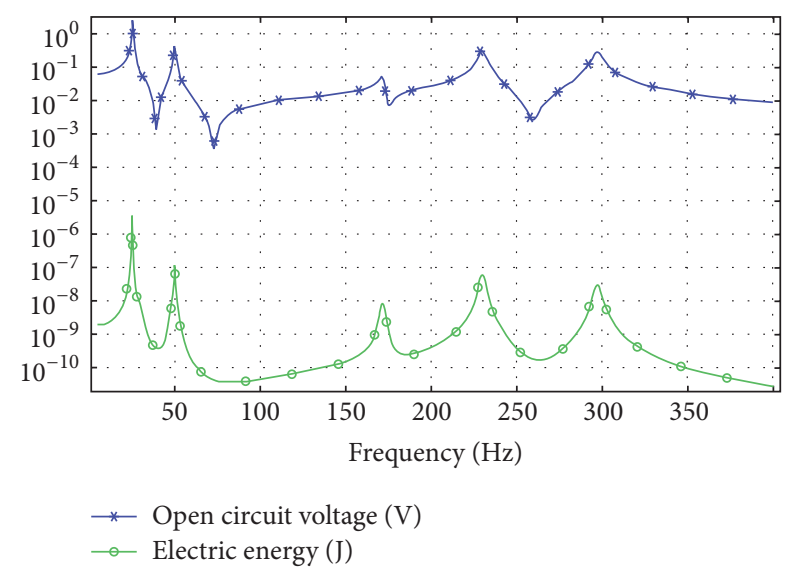

FIGURE 6: Electrical characteristics of the harvester.

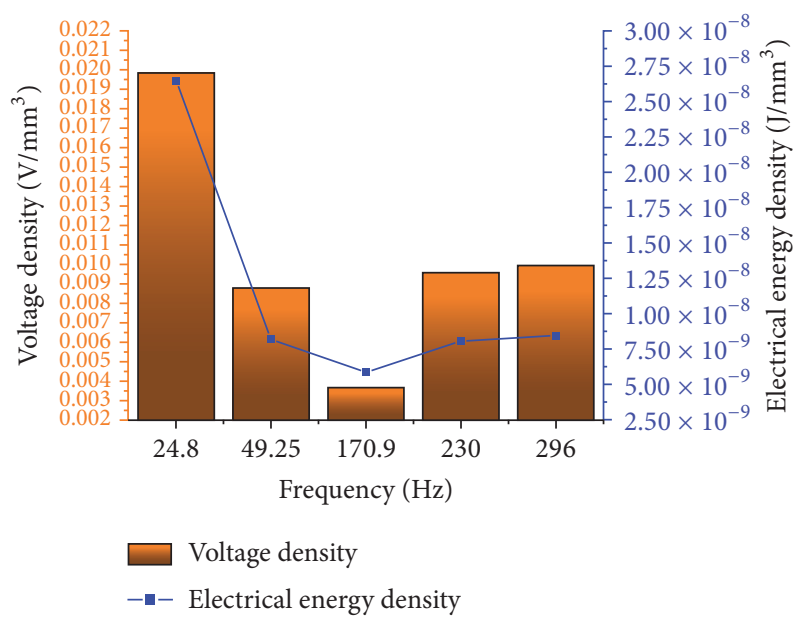

Figure 7: Comparison of electrical characteristics.

characteristics at the higher resonance frequencies could have the same values and harvester will be able to provide lower but stable energy feed to the load.

Open circuit voltage and electrical energy were investigated as electrical characteristics of the energy harvester. Frequency domain study was used for this investigation. Results are given in Figure 6.

Analysis of the electrical characteristics showed that maximum open circuit and electrical energy densities were achieved at the lowest resonant frequency and it is equal to $19.85 \mathrm{mV} / \mathrm{mm}^{3}$ and $26.4 \mathrm{~nJ} / \mathrm{mm}^{3}$, respectively. Such electrical characteristics were obtained because of the dominant first out-of-plane bending mode and uniform strain distribution at the piezoceramic layers. However, electrical characteristics at the higher resonant frequencies are lower. On the other hand, it can be noticed that electrical characteristics obtained at higher frequencies have similar values. So, it shows that energy harvester is able to provide adequately stable energy feed at different resonant frequencies. Comparison of electrical characteristics is given in Figure 7.

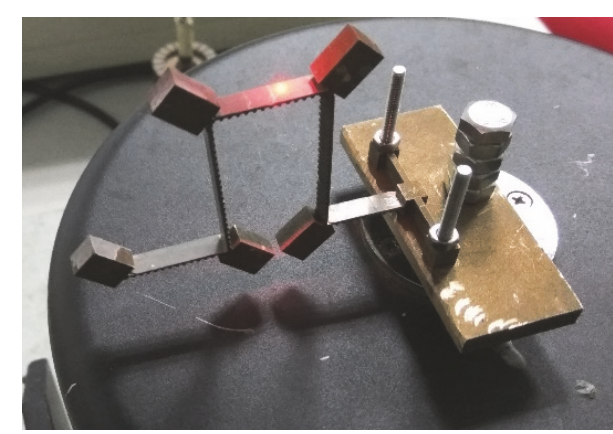

FIGURE 8: Prototype of the energy harvester.

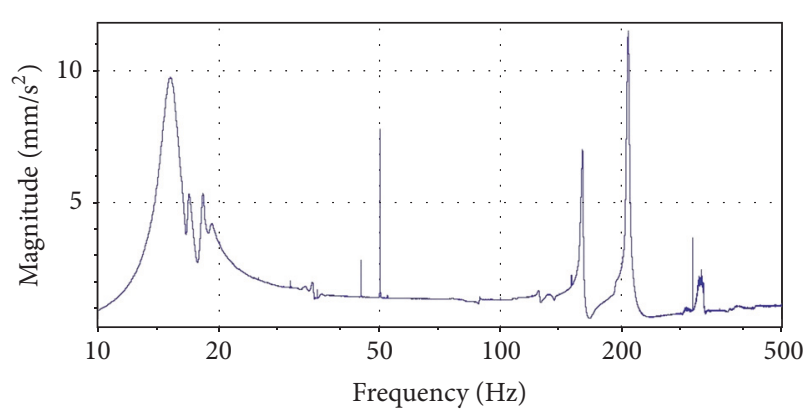

Figure 9: Frequency response characteristics of the harvester.

\section{Experimental Investigation of the Multifrequency Energy Harvester}

Experimental investigation of the multifrequency energy harvester was performed in order to validate results obtained during numerical investigation. Prototype was made with strict respect to geometrical and physical parameters used for the numerical model. View of the prototype is given in Figure 8.

Firstly, experimental study of frequency response characteristics was performed with the aim of validating results of numerical investigation. OFV 056 scanning vibrometer (Polytec, Germany) was employed for this purpose. Result of the tip vibration measurement in frequency domain is given in Figure 9.

It can be seen that frequency response characteristic obtained experimentally has good coincidence with the results of numerical simulation. The highest difference between resonant frequencies obtained numerically and experimentally is $22.6 \mathrm{~Hz}$. Also, analysis of the results revealed that mechanical quality factor of the system at the first resonant frequency is much lower compared to the other resonant frequencies. So, it can be said that harvester operation at the first resonant frequency will be more stable during fluctuations in excitation frequency. In order to assess differences in frequency response characteristics, comparison of the resonant frequencies was made. Results are given in Figure 10.

Comparison of the resonant frequencies showed that resonant frequencies obtained experimentally are lower compared to the frequencies obtained numerically except the fifth resonant frequency. Differences are caused by errors which 


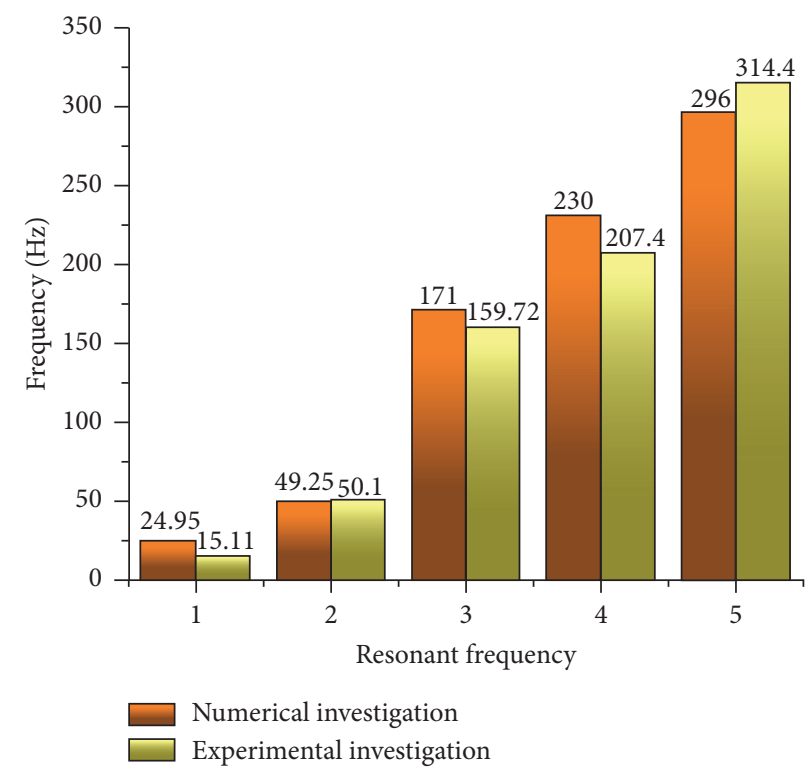

FIGURE 10: Comparison of the resonance frequencies.
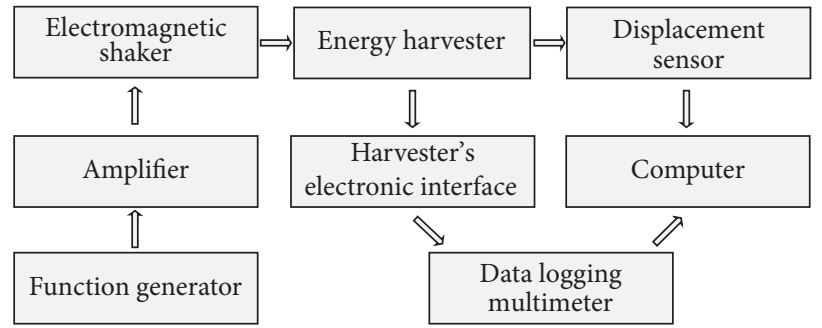

FIGURE 11: Neat diagram of the experimental setup.

occurred during the prototype manufacturing, mismatches in material properties, and glue layer, which was neglected in the numerical model. However, differences are in adequate range and on the basis of this it can be concluded that results of the numerical investigation have good agreement with experimental investigation.

Experimental investigations of the electrical characteristics were performed as well. Aim of investigation was to obtain electrical output characteristics of the harvester from view point of open circuit voltage and generated energy densities. For this purpose, experimental setup and electronic interface were built. Neat diagram of the experimental setup is given in Figure 11.

The experimental setup consists of the function generator and amplifier which were used for electromagnetic shaker driving. The displacement sensor and data logging multimeter were used to measure base displacement and output voltage amplitudes during whole investigation. In order to record and manage data, the displacement sensor and multimeter were connected to the computer with special software. Electronic interface was specially designed and manufactured for experimental setup (Figure 12).
The electrical interface represents classical AC/DC converter with single output and multichannel output operation modes. So, it consists of five full wave diode bridges which are made of BAT46 (Vishay Semiconductors, Germany) low-loss Schottky diodes (D1-D20). Therefore, at multichannel operation mode, the diode bridges are in parallel and form fivechannel AC/DC converter with $47 \mu \mathrm{F}$ electrolytic capacitors (C1-C5) as energy storage buffers. Multichannel operation mode gives possibility of separately converting and storing energy generated by different piezoceramic layers. Moreover, the electrical interface could be switched to one-channel mode. It means that DC outputs of each channel will be connected to common $220 \mu \mathrm{F}\left(C_{\text {Com }}\right)$ electrolytic energy storage capacitor. Single-channel operation mode gives possibility of converting and storing energy from different piezoceramic layers which operate at different deformation modes. Moreover, designed AC/DC converter can be connected in cascades to increase number of the channels.

Investigation of open circuit voltage at resonant frequencies was performed. Voltage was measured separately at each piezoceramic layer. For this investigation, the experimental setup, without electronic interface, was used. Voltage was 


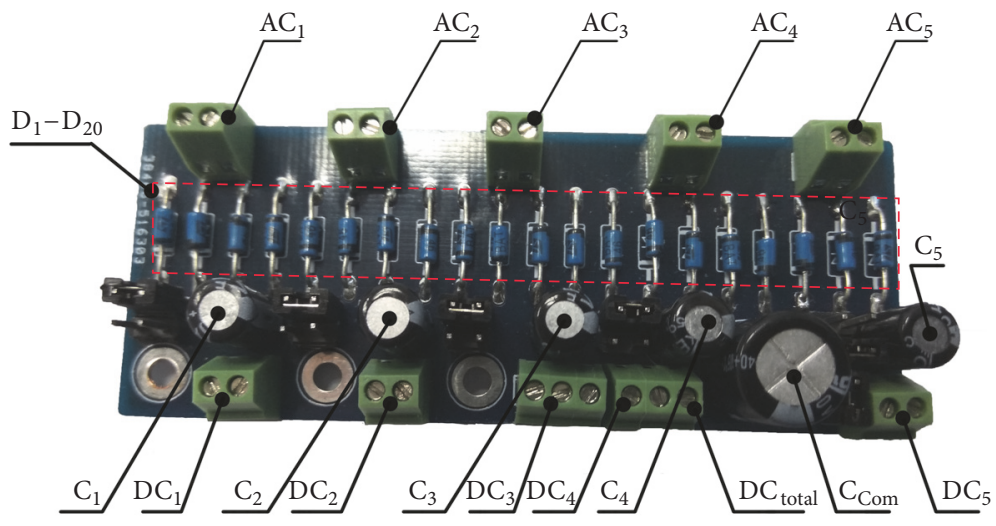

FIGURE 12: Electronic interface for the energy harvester.

measured and recorded by the data logging voltmeter and computer. Base displacement, during this stage of the investigation, was $100 \mu \mathrm{m}$ and it was measured by the displacement sensor. Results of the investigation are given in Figure 13.

Analysis of open circuit voltage characteristics showed that voltage distribution at the energy harvester during its excitation at the first resonance frequency has linear behavior (Figure 13(a)). Such voltage characteristic shows that whole harvester operates at the first, out-of-plane, bending mode (Figure 5). Therefore, open circuit voltage characteristics confirm the results of frequency response and modal analysis. Moreover, the highest open circuit voltages obtained at the first resonant frequency are $5.4 \mathrm{~V}$ and $5.6 \mathrm{~V}$. They were achieved at $\mathrm{PZT}_{1}$ and $\mathrm{PZT}_{2}$ piezoceramic layers.

Figure 13(b) represents open circuit voltage characteristics of the energy harvester at second resonance frequency. The highest open circuit voltage levels were achieved at $\mathrm{PZT}_{2}$ and $\mathrm{PZT}_{3}, 2.8 \mathrm{~V}$ and $2.63 \mathrm{~V}$, respectively. This shows that the highest strain is at junction between cantilevers $L_{1}$ and $L_{2}$. On the basis of this, it can be concluded that displacement of the harvester's body has longitudinal behavior and operates at compound of the first and second bending modes.

Open circuit voltage characteristics of the energy harvester at the third resonance frequency are given in Figure 13(c). Analysis of the characteristics revealed that the highest open circuit voltage levels were achieved at $\mathrm{PZT}_{1}$, $\mathrm{PZT}_{3}, \mathrm{PZT}_{8}$, and $\mathrm{PZT}_{11}$, with values $0.88 \mathrm{~V}, 0.86 \mathrm{~V}, 0.87 \mathrm{~V}$, and $0.91 \mathrm{~V}$, respectively. On the basis of the open circuit voltage peaks, it can be concluded that harvesters operation at the third resonance frequency is based on the second out-ofplane bending mode and its compounds.

Figure 13(d) represents open circuit voltage characteristics of the harvester at fourth resonance frequency. Analysis of the characteristics showed that the highest voltage values were achieved at $\mathrm{PZT}_{1}$ and $\mathrm{PZT}_{3}$ layers. Open circuit voltage values reached $1.21 \mathrm{~V}$ and $0.8 \mathrm{~V}$, respectively. At this resonance frequency, voltage levels are lower compared to the abovementioned cases. On the other hand, the harvester at the first three resonance frequencies operates at the first, out-of-plane, mode or compounds of the first and second mode. On the basis of the modal analysis and the results of experimental investigation, it can be said that dominant mode at that frequencies is the first. However, at the fourth and fifth resonance frequencies, the dominant mode is the second. So, such modes distribution at the cantilevers in higher resonance frequencies lead to lower voltage levels.

Finally, analysis of the open circuit characteristics at the fifth resonance frequency showed that the highest voltage values were achieved at $\mathrm{PZT}_{1}$ and $\mathrm{PZT}_{3}$ (Figure 13(e)). Open circuit values reached $0.93 \mathrm{~V}$ and $0.71 \mathrm{~V}$, respectively. Moreover, analysis revealed that characteristics of the fourth and fifth characteristics have coincidence in behavior and voltage levels. So, this confirms that energy harvester operation at higher resonance frequencies is based on the second, out-ofplane, bending mode or compounds of the second and first modes.

Open voltage characteristics represent values obtained from different piezoceramic layers, in order to accurately assess harvester's efficiency at different resonance frequencies; comparison from view point of voltage density was performed. Results of the comparison are given in Figure 14.

Comparison revealed that the highest open circuit voltage density is at the first resonance frequency. Voltage density at the first resonant frequency at least 3.12 times higher compared to other frequencies. On the other hand, voltage densities at higher frequencies are not in such extreme difference. Therefore, it can be concluded that the highest open circuit voltage density will be achieved at the lowest excitation frequencies. On the other hand, energy harvester is able to provide lower, but stable open circuit voltage density at the higher resonant frequencies.

Next stage of the investigation was dedicated to energy density at the resonance frequencies. For this purpose, the experimental setup with electronic interface switched to multichannel mode was used. Energy generated by each piezoceramic layer was stored and measured on $47 \mu \mathrm{F}$ capacitor. Measurements were performed at each channel by the data logging voltmeter. Energy harvester's base displacement, during whole experimental investigation, was $100 \mu \mathrm{m}$. Results of the investigation are given in Figure 15.

Analysis of the results showed that highest energy density at the first resonant frequency reached $84 \mu \mathrm{J} / \mathrm{mm}^{3}$ and 


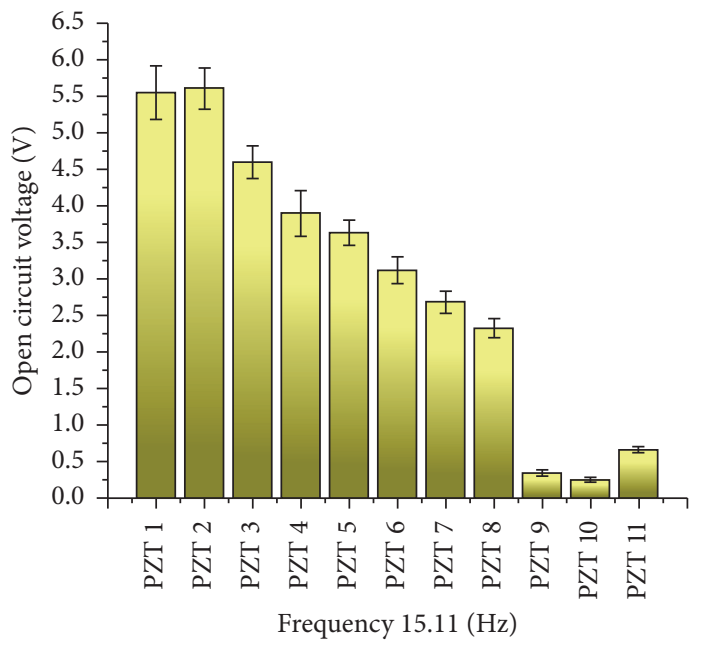

(a)

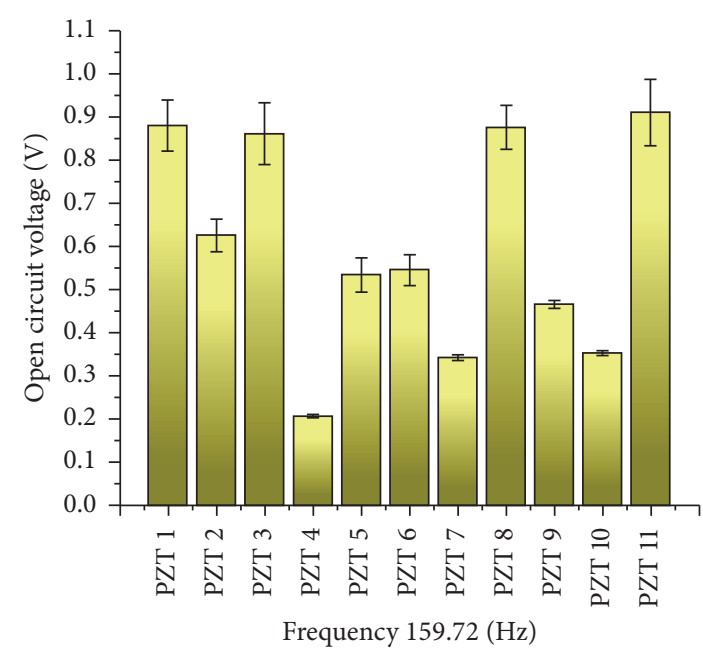

(c)

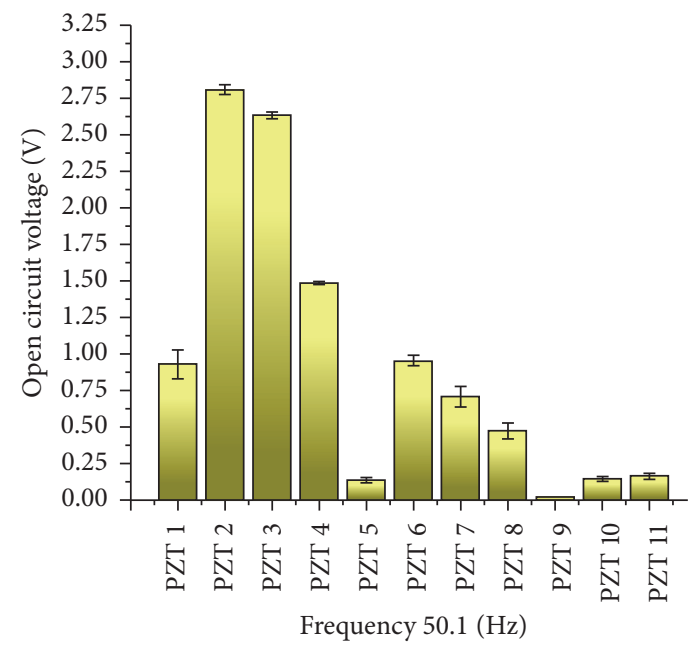

(b)

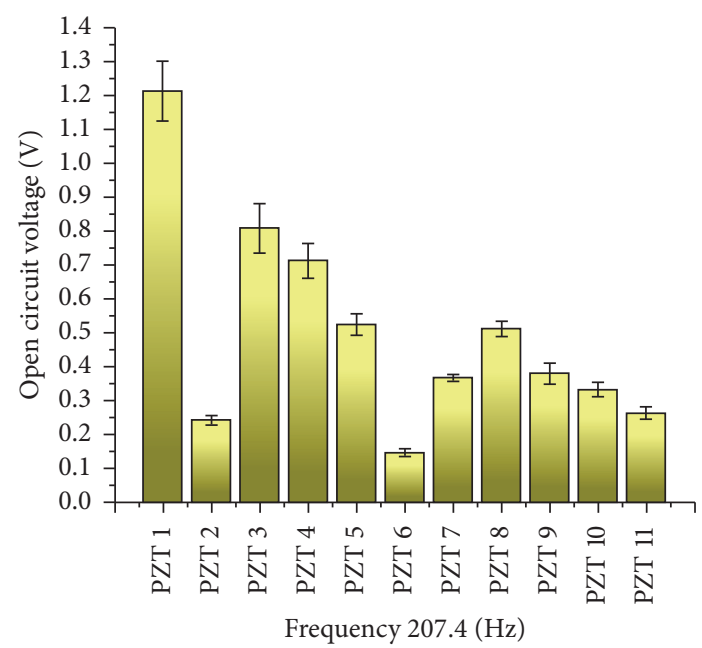

(d)

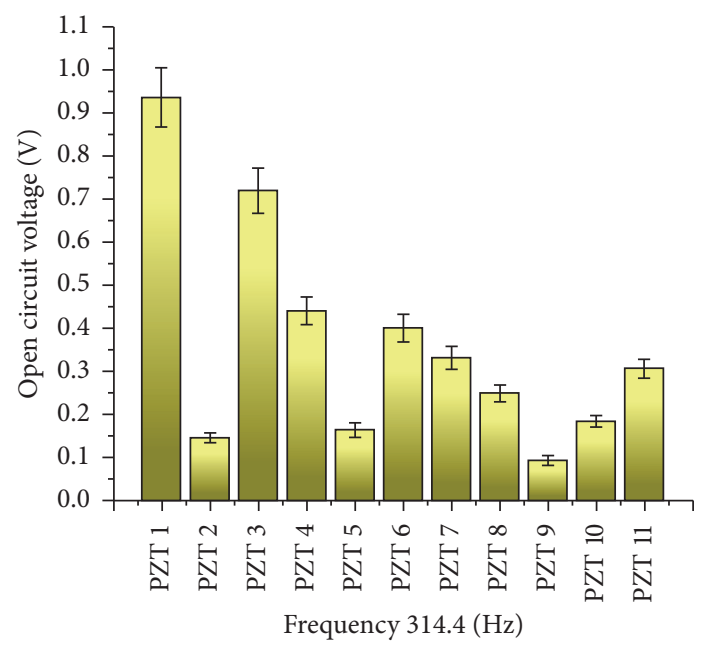

(e)

FIGURE 13: Open circuit voltage characteristics at the resonant frequencies: at (a) $15.11 \mathrm{~Hz}$; (b) $50.1 \mathrm{~Hz}$; (c) $159.72 \mathrm{~Hz}$; (d) $207.4 \mathrm{~Hz}$; (e) $314.4 \mathrm{~Hz}$. 


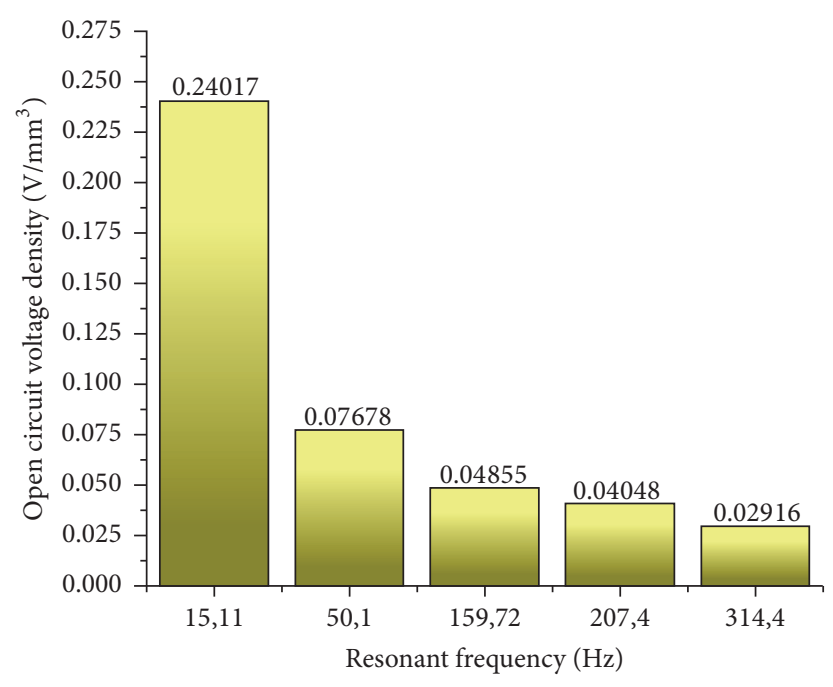

FIGURE 14: Open circuit voltage density characteristics.

it was generated by $\mathrm{PZT}_{1}$ piezoceramic layer. Also, the results revealed that the highest energy densities at the first resonance frequency were achieved near-fixed end of the harvester. So, on the basis of the experimental investigation, it could be concluded that the highest energy density concentration is near-fixed end of the harvester when the first bending mode is dominant.

Analysis of the energy densities at the second resonant frequency showed that highest values reached $22.17 \mu \mathrm{J} / \mathrm{mm}^{3}$ and $15.37 \mu \mathrm{J} / \mathrm{mm}^{3}$ at $\mathrm{PZT}_{2}$ and $\mathrm{PZT}_{3}$, respectively. However, maximum energy density at the first resonant frequency is 3.78 times higher. On the other hand, the first resonant frequency represents pure first, out-of-plane, bending mode while the second resonance frequency stands for compound of the first and second bending modes.

Results of the experimental investigation related to the third resonance frequency showed that the highest energy densities were achieved at piezoceramic layers $\mathrm{PZT}_{1}$ and $\mathrm{PZT}_{11}$ with values $2.44 \mu \mathrm{J} / \mathrm{mm}^{3}$ and $2.5 \mu \mathrm{J} / \mathrm{mm}^{3}$, respectively. However, energy densities levels are much lower compared to the first two resonance frequencies, but on the other hand its distribution is more even. Therefore, at this resonance frequency, the energy harvester is able to provide stable energy feed to the energy storage device.

Figures 15(d) and 15(e) revealed that energy harvester has much lower energy densities at the fourth resonant frequencies. Only $\mathrm{PZT}_{1}$ generated suitable energy density, that is, $6.61 \mu \mathrm{J} / \mathrm{mm}^{3}$. On the other hand, distribution of the energy densities at the fifth resonance frequency showed more stable characteristics with maximum values generated by $\mathrm{PZT}_{1}$ and $\mathrm{PZT}_{7}$. Energy densities at these piezoceramic layers reached $26.11 \mathrm{~nJ} / \mathrm{mm}^{3}$ and $25.75 \mathrm{~nJ} / \mathrm{mm}^{3}$, respectively. Considering much lower values, energy density characteristics at the fifth resonance frequency are more stable compared to the fourth resonance frequency.

In order to assess total energy densities at the resonance frequencies, electronic interface was switched to one-channel mode with one common $220 \mu \mathrm{F}$ energy storage capacitor.
Energy harvester's base displacement during this investigation was $100 \mu \mathrm{m}$. Results of the investigation are given in Figure 16.

During analysis of Figure 16, it becomes obvious that the highest energy density was achieved at the first resonance frequency. Its value reached $30.8 \mu \mathrm{J} / \mathrm{mm}^{3}$. This value is much higher compared to the other energy densities values. Such difference occurred due to the higher strain levels at cantilever beams which were achieved by modifications of the cross-sectionsal areas and the dominant first, out-of-plane, mode. On the other hand, energy harvesters operation at the higher resonance frequencies could provide suitable energy densities for practical implementation.

\section{Conclusions}

The numerical and experimental investigations of the multifrequency energy harvester were performed. Numerical investigation showed that energy harvester has five resonant frequencies. Modal analysis of the harvester showed that it operates at dominant 1st and 2nd out-of-plane bending mode of the beams and combination of these modes. Multimodal operation principle ensures strain summation at every resonance frequency of the harvester. Results of the frequency response investigation showed that energy harvester could be used for multifrequency energy harvesting at five resonant frequencies which are located at frequency range from $15 \mathrm{~Hz}$ to $300 \mathrm{~Hz}$. Analysis of the calculated electrical characteristics of the harvester showed that maximum open circuit and electrical energy densities are achieved at the lowest resonant frequency.

The experimental investigation of frequency response characteristic confirmed that energy harvester has five resonant frequencies. The highest difference between resonant frequencies obtained during numerical and experimental investigations is $22.4 \mathrm{~Hz}$. Experimental measurements confirmed that proposed energy harvester is able to provide total energy density equal to $30.8 \mu \mathrm{J} / \mathrm{mm}^{3}$. 


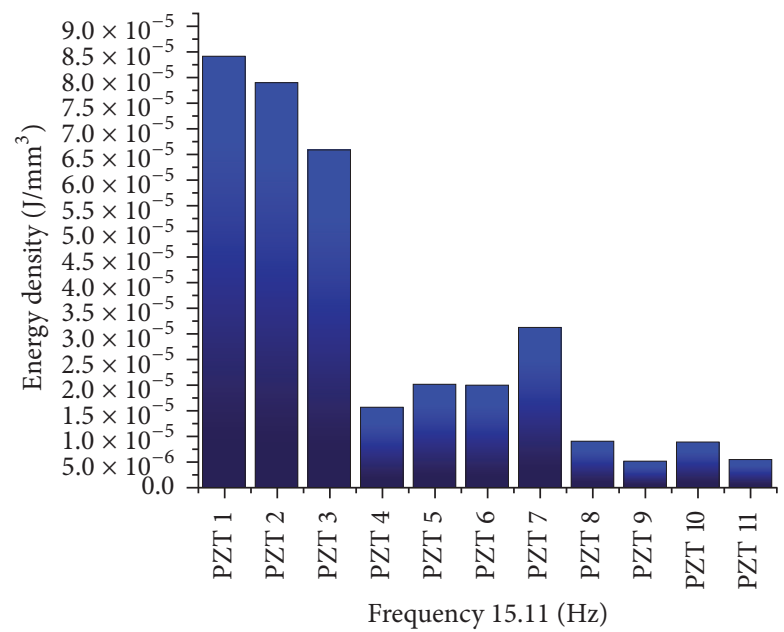

(a)

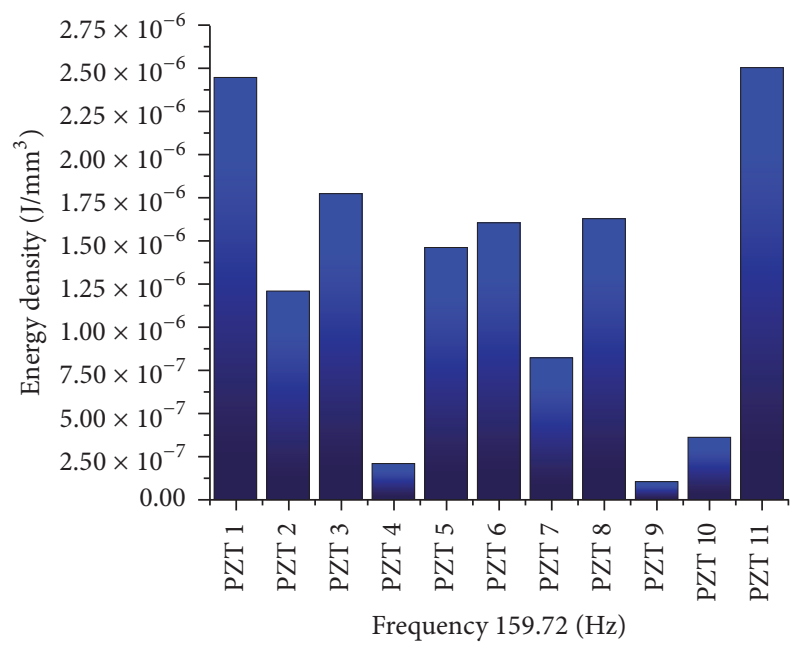

(c)

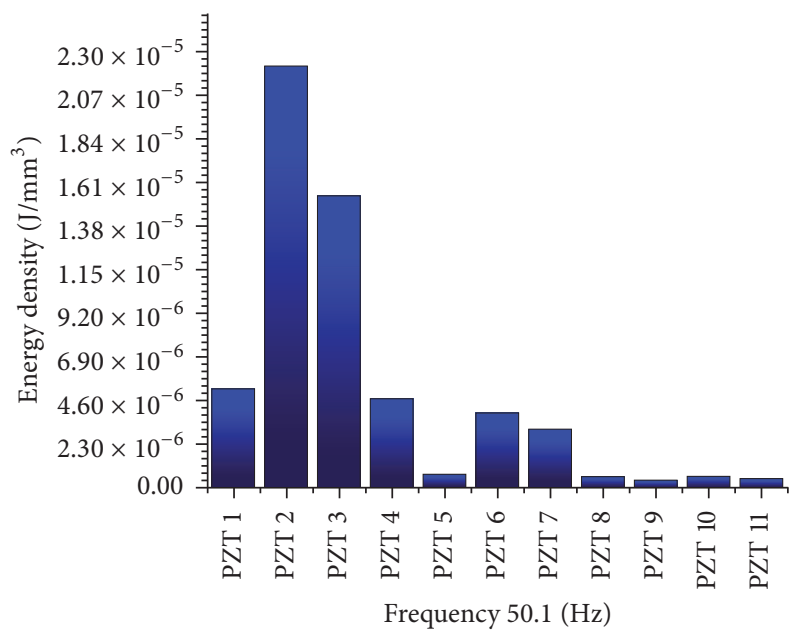

(b)

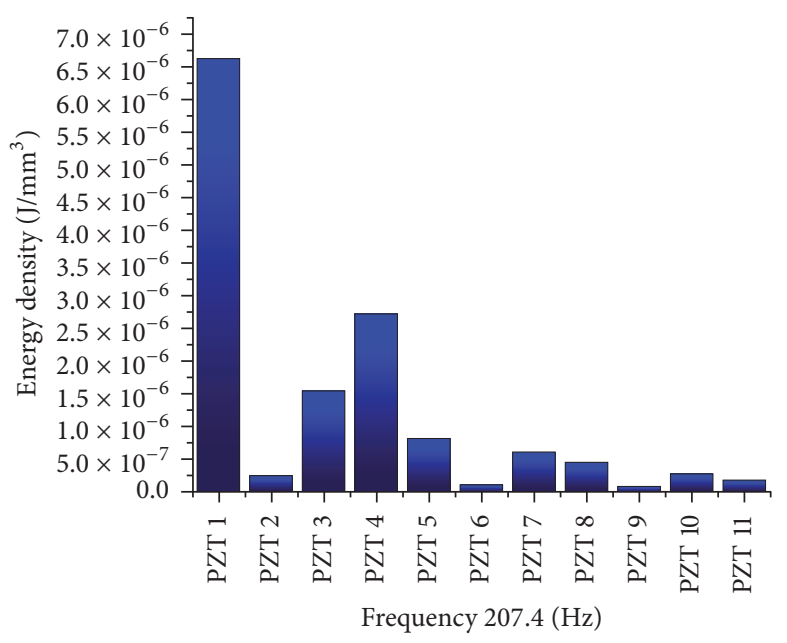

(d)

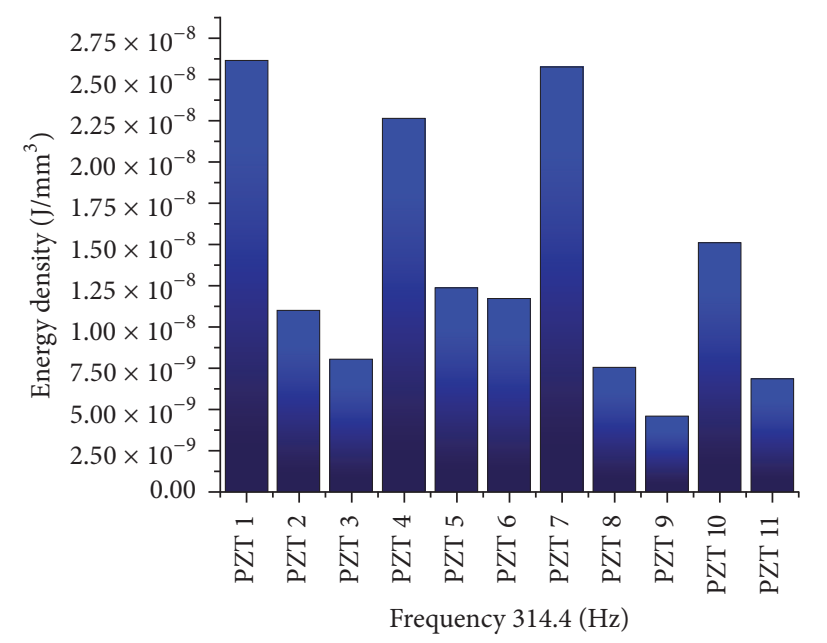

(e)

FiguRE 15: Energy density characteristics of the harvester at resonant frequencies: at (a) $15.11 \mathrm{~Hz}$; (b) $50.1 \mathrm{~Hz}$; (c) $159.72 \mathrm{~Hz}$; (d) $207.4 \mathrm{~Hz}$; (e) $314.4 \mathrm{~Hz}$. 


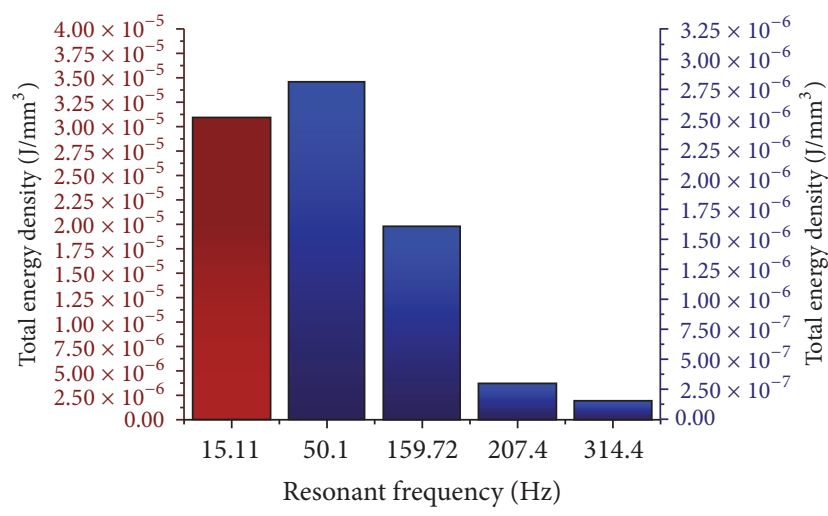

FIgURE 16: Total energy densities at the resonance frequencies.

\section{Conflicts of Interest}

The authors declare that there are no conflicts of interest regarding the publication of this paper.

\section{References}

[1] Y. K. Tan, Energy Harvesting Autonomous Sensor Systems: Design, Analysis and Practical Implementation, Taylor \& Francis, 2012.

[2] S. Roundy, P. K. Wright, and J. M. Rabaey, Energy Scavenging for Wireless Sensor Networks, Springer, New York, NY, USA, 2004.

[3] S. Priya and D. J. Inman, Energy Harvesting Technologies, Springer, New York, NY, USA, 2009.

[4] D. Spreemann and Y. Manoli, Electromagnetic Vibration Energy Harvesting Devices, Springer, New York, NY, USA, 2012.

[5] S. Roundy, P. K. Wright, and J. M. Rabaey, Energy Scavenging for Wireless Sensor Networks with Special Focus on Vibrations, Springer, New York, NY, USA, 2004.

[6] A. Erturk and D. J. Inman, Piezoelectric Energy Harvesting, John Wiley and Sons, Hoboken, NJ, USA, 2011.

[7] A. G. A. Muthalif and N. H. D. Nordin, "Optimal piezoelectric beam shape for single and broadband vibration energy harvesting: Modeling, simulation and experimental results," Mechanical Systems and Signal Processing, vol. 54-55, pp. 417-426, 2015.

[8] D. Benasciutti, L. Moro, S. Zelenika, and E. Brusa, "Vibration energy scavenging via piezoelectric bimorphs of optimized shapes," Microsystem Technologies, vol. 16, no. 5, pp. 657-668, 2010.

[9] M. Rosa and C. de Marqui Jr., "Modeling and analysis of a piezoelectric energy harvester with varying cross-sectional area," Shock and Vibration, vol. 2014, Article ID 930503, 9 pages, 2014.

[10] S. Ben Ayed, A. Abdelkefi, F. Najar, and M. R. Hajj, "Design and performance of variable-shaped piezoelectric energy harvesters," Journal of Intelligent Material Systems and Structures, vol. 25, no. 2, pp. 174-186, 2014.

[11] Q. C. Guan, B. Ju, J. W. Xu, Y. B. Liu, and Z. H. Feng, "Improved strain distribution of cantilever piezoelectric energy harvesting devices using $\mathrm{H}$-shaped proof masses," Journal of Intelligent Material Systems and Structures, vol. 24, no. 9, pp. 1059-1066, 2013.

[12] X. Ma, A. Wilson, C. D. Rahn, and S. Trolier-McKinstry, "Efficient Energy Harvesting Using Piezoelectric Compliant
Mechanisms: Theory and Experiment," Journal of Vibration and Acoustics, vol. 138, no. 2, Article ID 021005, 2016.

[13] A. R. Reddy, M. Umapathy, D. Ezhilarasi, and G. Uma, "Cantilever beam with trapezoidal cavity for improved energy harvesting," International Journal of Precision Engineering and Manufacturing, vol. 16, no. 8, pp. 1875-1881, 2015.

[14] B. Ahmed, G. Despesse, S. Boisseau, and E. Defay, "Strategies for wideband mechanical energy harvester," in Small-Scale Energy Harvesting, 2012.

[15] T. J. Kazmierski and S. Beeby, Energy Harvesting Systems, Springer, New York, NY, USA, 2011.

[16] A. Čeponis and D. Mažeika, "Multi-frequency piezoelectric energy harvester based on the square type cantilever array," in Mechanika 2017: Proceedings of the 22nd International Scientific Conference, 19 May 2017, Kaunas University of Technology, Lithuania, pp. 81-87, 2017. 


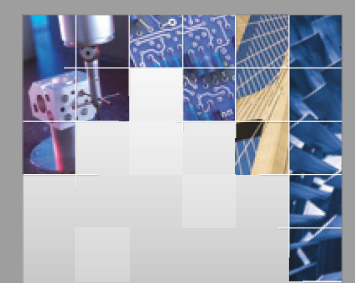

\section{Enfincering}
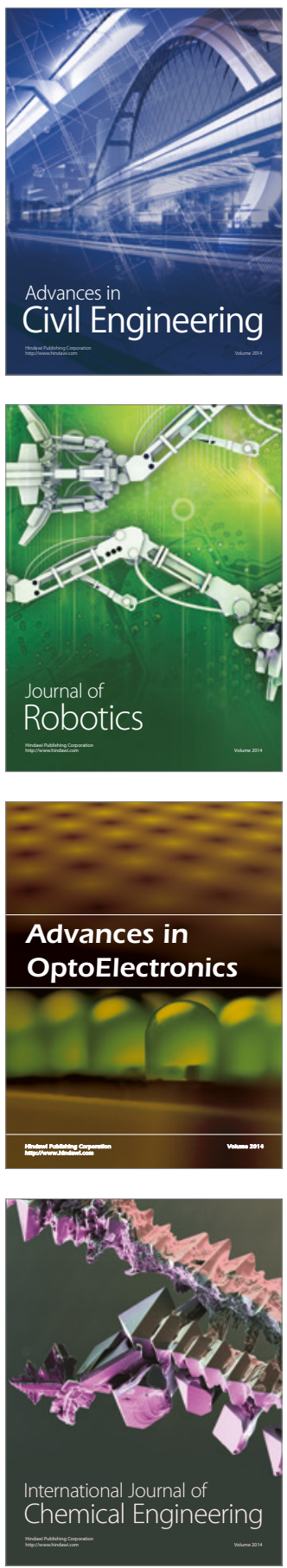

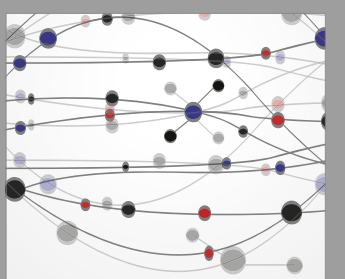

The Scientific World Journal

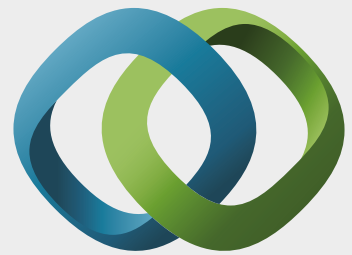

\section{Hindawi}

Submit your manuscripts at

https://www.hindawi.com
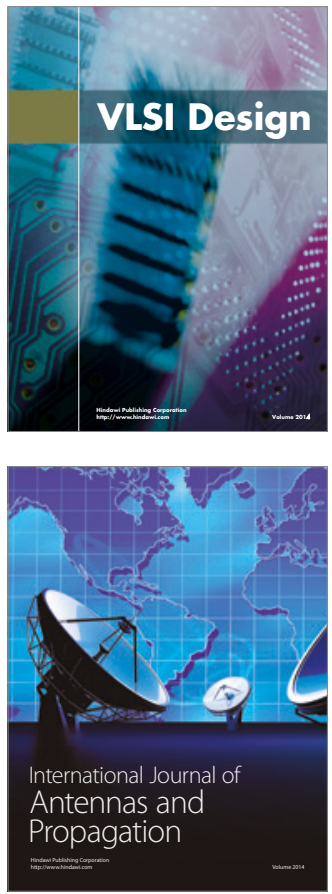

\section{Rotating}

Machinery
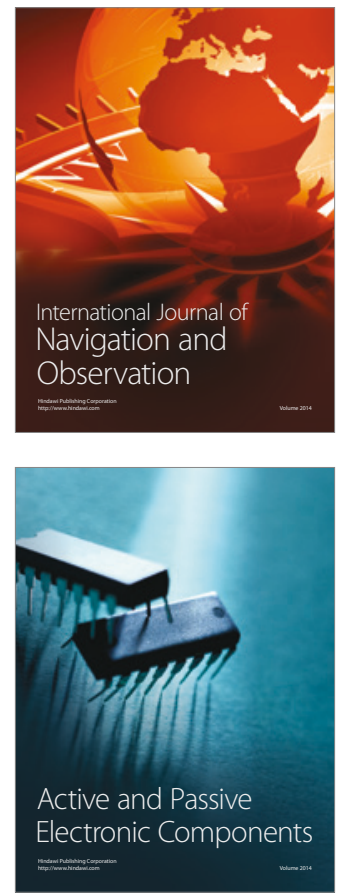
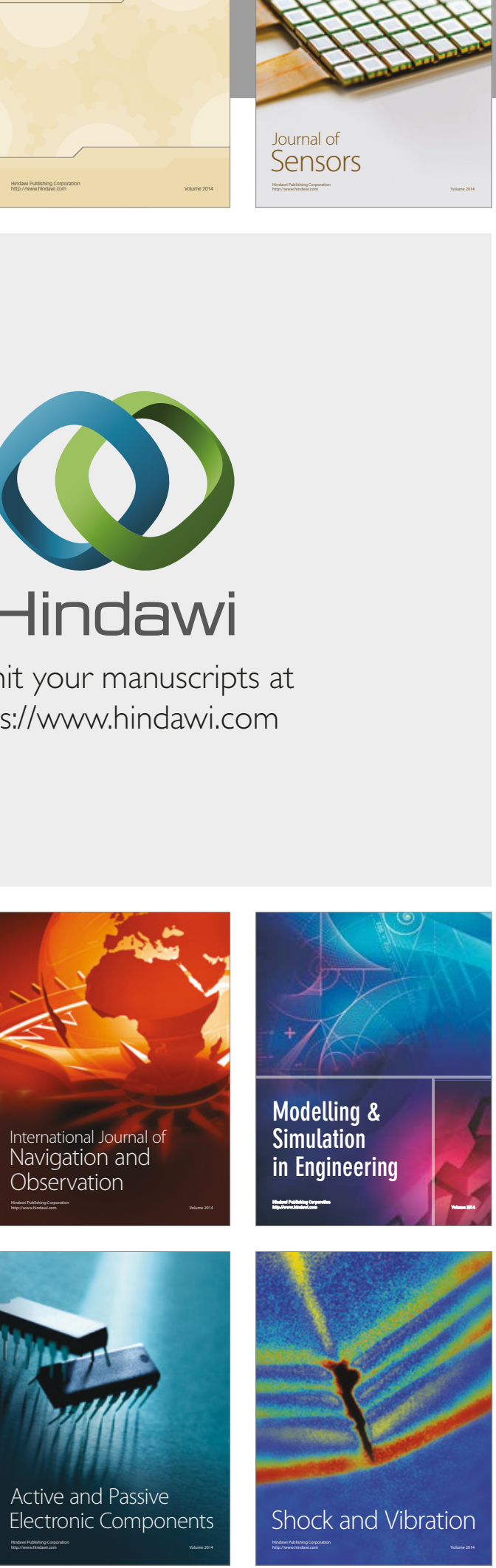
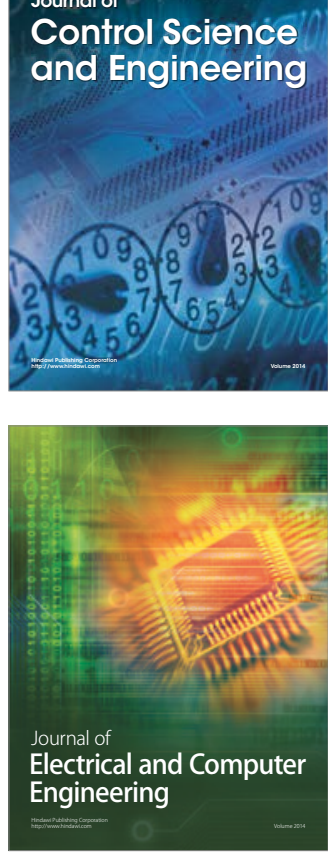

Distributed

Journal of

Control Science

and Engineering
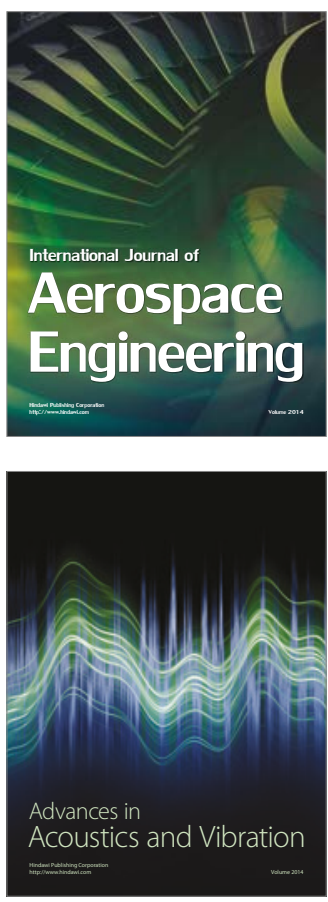

Sensor Networks 